\title{
Repair versus Debridement for Acetabular Labral Tears-A Systematic Review
}

\author{
Eoghan T. Hurley, M.B., B.Ch., M.Ch., Andrew J. Hughes, F.R.C.S.I. (Tr \& Orth), \\ M. Shazil Jamal, M.R.C.S., Edward S. Mojica, B.S., David A. Bloom, M.D., \\ Thomas Youm, M.D., and Tom McCarthy, F.R.C.S.I. (Tr \& Orth)
}

\begin{abstract}
Purpose: The purpose of this study was to systematically review the evidence in the literature to ascertain whether acetabular labral repair (ALR) or debridement (ALD) resulted in superior patient outcomes. Methods: The systematic review was conducted in accordance with the Preferred Reporting Items for Systematic Reviews and Meta-Analyses guidelines. Peer-reviewed studies comparing ALR and ALD published in English with full text available were included. Patients undergoing both open and arthroscopic surgery in randomized controlled trials, prospective cohort studies, retrospective cohort studies, and case-control studies were included. Studies were quantified for methodological quality using the MINORS criteria. Clinical outcomes were compared, with qualitative analysis, and quantitative analyses were performed using GraphPad Prism version 7. A $P$ value $<.05$ was considered to be statistically significant. Results: There were 8 studies included (level of evidence [LOE] I = 1; LOE II $=2$; LOE III $=5$ ). The 7 studies compared 364 patients (369 hips) with ALR to 318 patients (329 hips) with ALD, with a mean follow-up time ranging between 32-120 months. Five studies found significantly improved patient reported outcomes with ALR (Harris Hip Score, Merle d'Aubigné, Pain, SF-12). Several studies compared the outcomes after ALR and ALD and found statistical significance in all investigated metrics in favor of ALR. One study found a significant improvement in abduction but no other study found any difference in range of motion. No study found any difference in complication rate, revision rate or conversion to total hip arthroplasty. Although, 2 studies found ALR reduced the rate of osteoarthritic progression. Conclusion: Current literature suggests that acetabular labral repair may result in superior patient reported outcomes. However, there appears to be no significant difference in the rate of progression to total hip arthroplasty at up to 10-year follow-up. Level of Evidence: Level III, systematic review of Level I, II, and III studies.
\end{abstract}

$\mathbf{F}$ emoroacetabular impingement (FAI) syndrome can cause pain, dysfunction, and early arthritic progression. FAI syndrome occurs because of morphological abnormality of the bone in either the acetabular rim (pincer morphology) or femoral neck (cam

From New York University Langone Health, Department of Orthopaedic Surgery (E.T.H., E.S.M., D.A.B., T.Y), New York, New York, U.S.A., and Sports Surgery Clinic, Dublin (E.T.H., A.J.H., M.S.J., T.McC.), Ireland.

The authors report the following potential conflict of interest or source of funding: T.Y. reports personal fees from Arthrex. Full ICMJE author disclosure forms are available for this article online, as supplementary material.

Received May 4, 2020; accepted June 28, 2021.

Address correspondence to Eoghan Hurley, M.B., B.Ch., M.Ch., New York University Langone Health, Department of Orthopaedic Surgery, New York, NY, U.S.A.E-mail: eoghan.hurley@nyulangone.org

(C) 2021 THE AUTHORS. Published by Elsevier Inc. on behalf of the Arthroscopy Association of North America. This is an open access article under the CC BY license (http://creativecommons.org/licenses/by/4.0/).

2666-061X/20638

https://doi.org/10.1016/j.asmr.2021.06.008 morphology). Labral tears are common alongside FAI and occur in up to $55 \%$ of patients with mechanical symptoms, as a result of repetitive abnormal contact between the bone and labrum. ${ }^{1}$ Hip arthroscopy, while technically challenging, is increasingly being performed to treat FAI syndrome and associated pathologies..$^{2-4}$ Advantages over the open approach include faster rehabilitation and avoidance of a trochanteric osteotomy. ${ }^{4,5}$

In the recent past, acetabular labral debridement (ALD) has been used to treat labral pathology and has been shown to reduce symptoms associated with FAI. ${ }^{4,5}$ However, the labrum has been shown to play an important role in joint stability, increasing the acetabular joint area and reducing forces transmitted through the articular cartilage; thus acetabular labral repair (ALR) may be advantageous in preserving the hip joint and reduce the rate of osteoarthritic progression. ${ }^{6-9}$

There is limited evidence to suggest how such patients should be managed, nd whether labral tears should be 

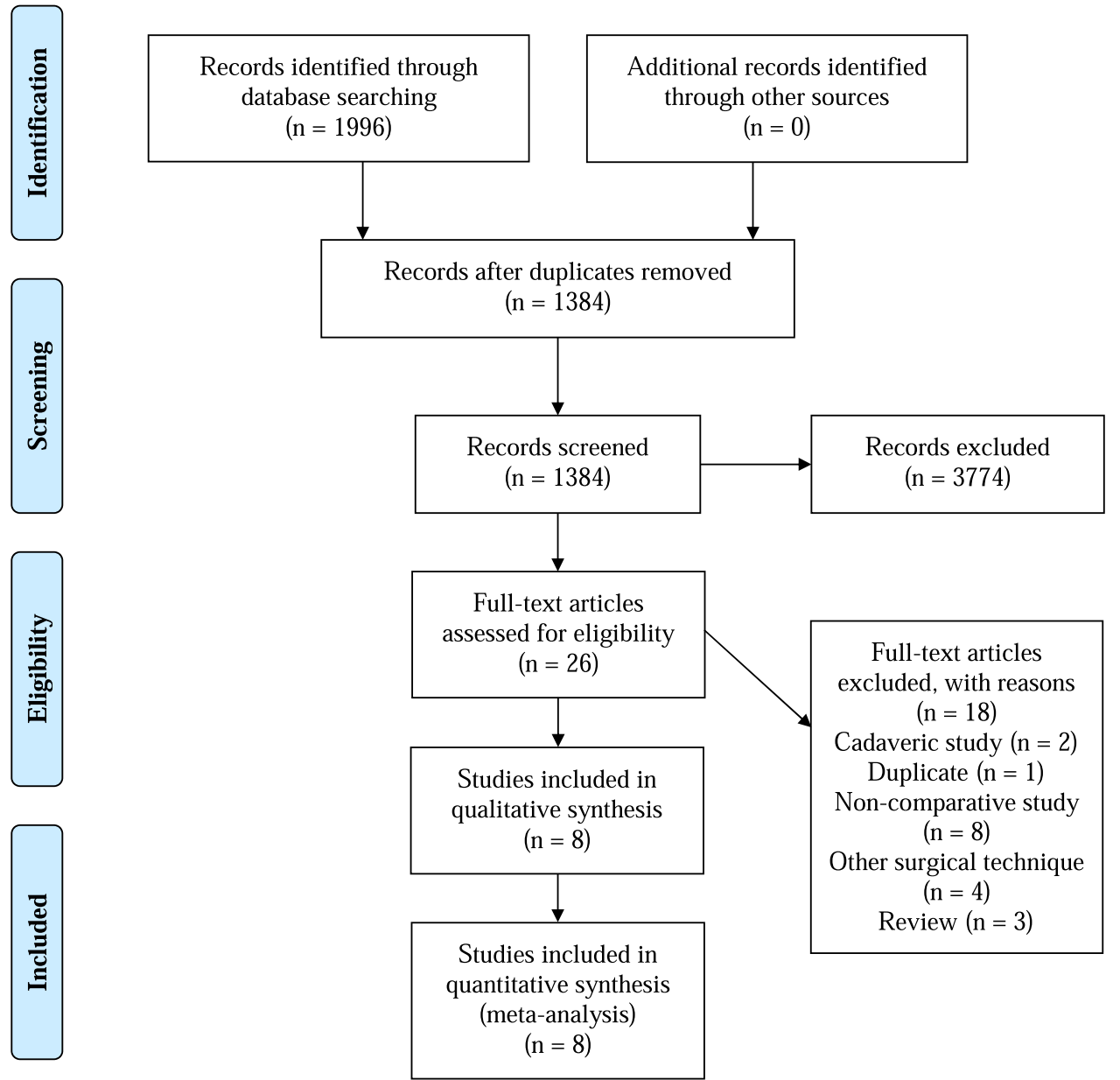

Fig 1. Preferred Reporting Items for Systematic Reviews and MetaAnalyses Study Selection Flow Diagram.

repaired, because to our knowledge only 1 randomized controlled trial comparing ALR to ALD exists. Additional comparative studies have been published in recent years, warranting an updated systematic review. The purpose of this study was to systematically review the evidence in the literature to ascertain whether ALR or ALD resulted in superior patient outcomes. Our hypothesis was that ALR would result in superior patient reported outcomes, with lower progression rates to total hip arthroplasty.

Table 1. Study Characteristics

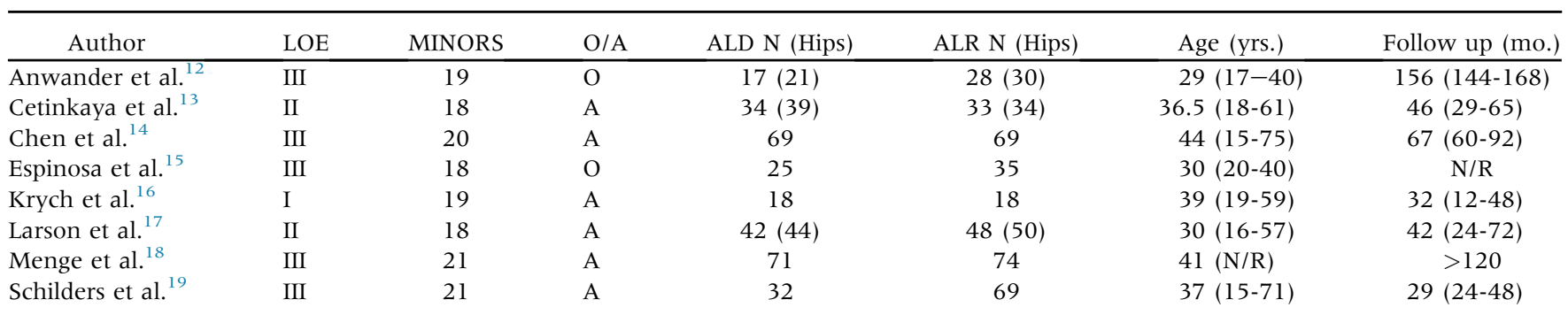

LOE, level of evidence; O/A, open/arthroscopic; ALD, debridement; ALR, repair; N, number; yrs, years; mo., months. 
Table 2. MINORS Score

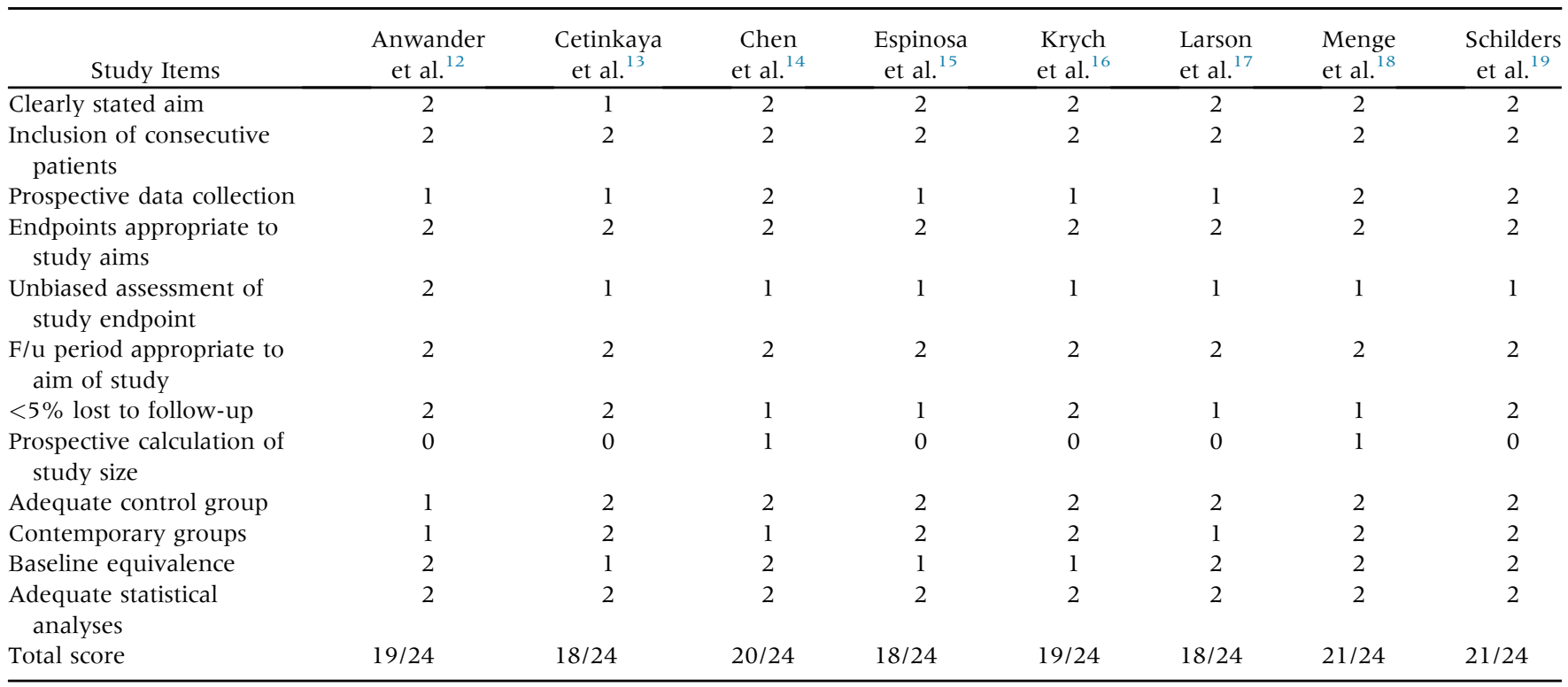

\section{Methods}

\section{Search Strategy and Study Selection}

The literature search was conducted by two independent reviewers based on the Preferred Reporting Items for Systematic Reviews and Meta-Analyses guidelines. $^{10}$ The MEDLINE, EMBASE, and The Cochrane Library databases were queried in April 2020 with the following search terms: (femoroacetabular or
FAI or hip or coxa or acetabulofemoral joint) and (impingement) and (repair or refixation or preservation or reattachment or debridement or resection). The search results were reviewed independently and compared, with a senior author arbitrating in the instance of disagreement. The title and abstract of all search results were reviewed, and the full text of potentially eligible studies was evaluated. The reference lists of the included studies and literature reviews were

Table 3. Functional Outcomes

\begin{tabular}{|c|c|c|c|c|c|c|c|c|}
\hline Study & HOS (ALR vs ALD) & $\begin{array}{c}\text { mHHS } \\
\text { (ALR vs ALD) }\end{array}$ & $\begin{array}{c}\text { SF-12 Score } \\
\text { (ALR vs ALD) }\end{array}$ & $\begin{array}{c}\text { SF-12 MCS } \\
\text { (ALR vs ALD) }\end{array}$ & $\begin{array}{c}\text { SF-12 PCS } \\
(\mathrm{ALR} \text { vS ALD) }\end{array}$ & $\begin{array}{l}\text { Patient Satisfaction } \\
\text { (ALR vs ALD) }\end{array}$ & $\begin{array}{c}\text { VAS } \\
\text { (ALR vS ALD) }\end{array}$ & $\begin{array}{c}\text { Merle d'Aubigné } \\
\text { (ALR vs ALD) }\end{array}$ \\
\hline $\begin{array}{l}\text { Anwander } \\
\text { et al. }{ }^{12}\end{array}$ & & & & & & & & $\begin{array}{l}5^{*}(3-6) \text { vs } \\
3.9(0-6)\end{array}$ \\
\hline $\begin{array}{c}\text { Cetinkaya } \\
\text { et al. }{ }^{13}\end{array}$ & $\begin{array}{c}87.2(50-99) \text { vs } \\
84.2(50-98)\end{array}$ & & & & & & $\begin{array}{l}2.3(0-3) \text { vs } \\
2.1(1-3)\end{array}$ & \\
\hline Chen et al. ${ }^{14}$ & $\begin{array}{c}76.8 \pm 24.7 \mathrm{vs} \\
74.8 \pm 21.4\end{array}$ & $\begin{array}{r}86.1 \pm 14.9 \mathrm{vs} \\
83.0 \pm 13.8\end{array}$ & & $\begin{array}{c}55.1 \pm 7.3 \mathrm{vs} \\
57.4 \pm 5.3\end{array}$ & $\begin{array}{c}48.9 \pm 9.5 \mathrm{vs} \\
48.7 \pm 7.6\end{array}$ & $\begin{array}{c}8.3 \pm 2.2 \mathrm{vs} \\
8.0 \pm 2.0\end{array}$ & $\begin{array}{c}2.0 \pm 2.3 \mathrm{vs} \\
2.3 \pm 2.0\end{array}$ & \\
\hline $\begin{array}{l}\text { Espinosa } \\
\quad \text { et al. }{ }^{15}\end{array}$ & & & & & & & & $\begin{array}{c}5.6^{*}(1-6) \mathrm{vs} \\
4.0(0-6)\end{array}$ \\
\hline Krych et al. ${ }^{16}$ & $\begin{array}{l}91.2^{*}(73-100) \text { vs } \\
80.9(43-100)\end{array}$ & & & & & $\mathrm{RNR}^{*}$ & & \\
\hline Larson et al. ${ }^{17}$ & & $94.3^{*}$ Vs 84.9 & $89.8^{*}$ vs 82.2 & & & & 0.7 vs 1.7 & \\
\hline Menge et al. ${ }^{18}$ & $\begin{array}{l}96(88-100) \text { vs } \\
96(89-100)\end{array}$ & $\begin{array}{l}85(63-99) \text { vs } \\
90(85-100)\end{array}$ & & & $\begin{array}{c}56(47-58) \text { vs } \\
56(51-58)\end{array}$ & 10 vs 10 & & \\
\hline $\begin{array}{l}\text { Schilders } \\
\text { et al. }{ }^{19}\end{array}$ & & $\begin{array}{c}93.6^{*}(55-100) \text { vs } \\
88.8(35-100)\end{array}$ & & & & & & \\
\hline
\end{tabular}

Range or Standard Deviation was not reported for Larson et al.

HOS; hip outcome score, mHHS; modified Harris Hip Score, SF-12; short form, MCS; mental score, PCS; physical score, VAS; visual analogue scale, ALD; debridement, ALR; repair.

*Denotes Statistical significance in favor of ALR. 


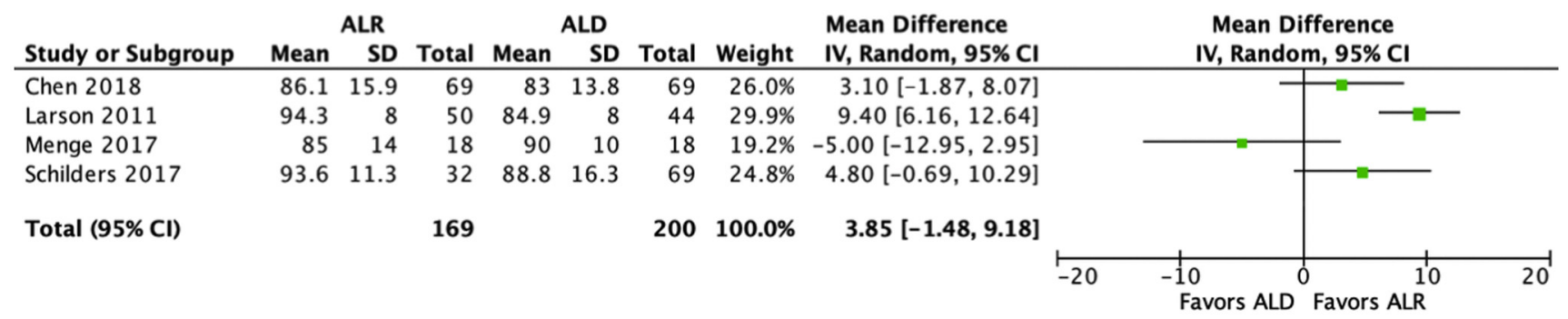

Fig 2. Forest Plot of the Harris Hip Score.

manually screened for additional articles meeting the inclusion criteria that were not identified during the initial search. There was no time limit with respect to publication date.

\section{Eligibility Criteria}

The inclusion criteria for this analysis were as follows: (1) studies comparing ALR and ALD, (2) published in a peer-reviewed journal, (3) published in English, and (4) full text of studies available. Study designs including randomized controlled trials, prospective cohort studies, retrospective cohort studies, and case control studies were considered for inclusion. The exclusion criteria were as follows: (1) case series, (2) review studies, (3) cadaver studies, (4) biomechanical studies, or (5) conference abstract only.

\section{Data Extraction/Analysis}

The relevant study characteristics including study design, level of evidence, methodological quality of evidence, patient population, outcome measures, and follow-up time points were collected by 2 independent reviewers using a predetermined data sheet. The results from each reviewer were compared. The MINORS (Methodological Index for Non-Randomised Studies) was used to evaluate the potential assessed risk of bias for each included study. ${ }^{11}$ The items were scored 0 if not reported, 1 if reported inadequately, and 2 if reported adequately; the global ideal score was 16 for noncomparative and 24 for comparative studies.

\section{Statistical Analysis}

Statistical analysis was performed using GraphPad Prism version 7. Qualitative analysis was performed for each study, and quantitative analysis was performed across all groups. Graphical representation of the comparative studies was performed using Review Manager ([RevMan; Macintosh]. Version 5.3. Copenhagen: The Nordic Cochrane Centre, The Cochrane Collaboration, 2014.).

\section{Results}

\section{Literature Search}

The initial literature search resulted in 1996 total studies. Once duplicates were removed and the articles were screened for inclusion and exclusion criteria, 1384 studies were included, and full texts were assessed for eligibility. Eight clinical studies with 682 patients $(698$ hips) were included in this review (Fig 1).

\section{Study Characteristics}

Eight studies were included (level of evidence [LOE] I; 1, LOE II; 2, LOE III; 5). The 8 studies compared 364 patients (369 hips) with ALR to 318 patients (329 hips) with ALD, with a mean follow-up time ranging between 32 to 120 months. ${ }^{12-19}$ Six studies used arthroscopic techniques, and 2 studies used an open approach to the hip. There was no significant difference between the cohorts in age, gender, concomitant cartilage injuries, or other reported baseline in the included

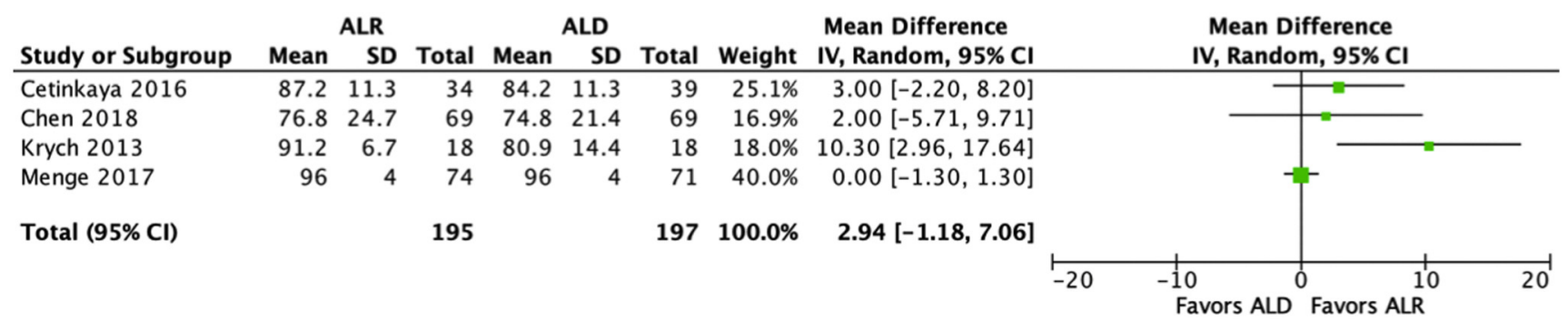

Fig 3. Forest Plot of the Hip Outcome Score. 


\begin{tabular}{|c|c|c|c|c|c|c|c|c|c|}
\hline \multirow[b]{2}{*}{ Study or Subgroup } & \multicolumn{3}{|c|}{ ALR } & \multicolumn{3}{|c|}{ ALD } & \multicolumn{2}{|r|}{ Mean Difference } & \multirow{2}{*}{$\begin{array}{c}\text { Mean Difference } \\
\text { IV, Random, } 95 \% \mathrm{CI}\end{array}$} \\
\hline & Mean & SD & Total & Mean & SD & Total & Weight & IV, Random, 95\% CI & \\
\hline Cetinkaya 2016 & 2.3 & 0.8 & 34 & 2.1 & 0.5 & 39 & $35.3 \%$ & $0.20[-0.11,0.51]$ & + \\
\hline Chen 2018 & 2 & 2.3 & 69 & 2.3 & 2 & 69 & $29.5 \%$ & $-0.30[-1.02,0.42]$ & - \\
\hline Larson 2011 & 0.7 & 0.5 & 50 & 1.7 & 1 & 44 & $35.2 \%$ & $-1.00[-1.33,-0.67]$ & - \\
\hline \multirow[t]{2}{*}{ Total $(95 \% \mathrm{Cl})$} & & & 153 & & & 152 & $100.0 \%$ & $-0.37[-1.23,0.50]$ & \\
\hline & & & & & & & & & $\begin{array}{ccc}-2 & 0 & 1 \\
\text { Favors ALR } & \text { Favors ALD }\end{array}$ \\
\hline
\end{tabular}

Fig 4. Forest Plot of the VAS Score.

studies. The study characteristics $\&$ patient demographics are reported in Table 1 , and the MINORS score are shown in Table 2.

\section{Functional Outcomes}

All 8 studies compared functional outcomes between patients treated with ALR and ALD (Table 3). Three studies compared patient satisfaction scores, with one study finding a significant difference in favor of ALR. Four studies compared modified Harris Hip Scores, with one study finding a significant difference in favor of ALR, as shown in Fig 2. Four studies compared Hip Outcome Scores, with one study finding a significant difference in favor of ALR as shown in Fig 3. Three studies compared SF-12 scores, with one study finding a significant difference in favor of ALR. Five studies ( 3 using VAS score, and 2 using the Merle d'Aubigné compared pain scores, with two studies finding a significant difference in favor of ALR, with the VAS score shown in Fig 4. Overall, 5 studies found significantly improved patient reported outcomes with ALR.

\section{Range of Motion}

Two studies compared range of motion between the two cohorts (Table 4), and one study found a significant difference in favor of ALR for abduction, but neither found a difference in flexion, extension, external rotation, internal rotation, or adduction.

\section{Revisions}

Six studies compared the rate of conversion to total hip arthroplasty (Table 5), with no study finding a significant difference in favor of either procedure, as shown in Fig 5. Additionally, 5 studies compared the rate of total revisions, with no study finding a significant difference in favor of either procedure, as shown in Fig 6.

\section{Complications and Osteoarthritic Progression}

Four studies compared complications between patients treated with ALR and ALD, with no study finding a significant difference in favor of either procedure (Table 6). However, 2 studies found the rate of overall osteoarthritic progression was significantly improved with ALR.

\section{Discussion}

The primary finding of this study is that ALR may result in superior patient-reported outcomes relative to ALD. This is best supported by the fact that 5 of 8 included studies reported that ALR resulted in superior outcomes with statistically significant differences when compared to ALD. To further bolster this argument, there were no statistically significant differences in the rate of total complications, the rate of total revisions, and the rate of conversion to total hip arthroplasty between these 2 procedures. Additionally, it should be

Table 4. Range of Motion

\begin{tabular}{|c|c|c|c|c|c|c|}
\hline Study & $\begin{array}{c}\text { Flexion } \\
\text { (ALR vs ALD) }\end{array}$ & $\begin{array}{c}\text { Extension } \\
\text { (ALR vs ALD) }\end{array}$ & $\begin{array}{c}\text { External Rotation } \\
\text { (ALR vs ALD) }\end{array}$ & $\begin{array}{c}\text { Internal Rotation } \\
\text { (ALR vs ALD) }\end{array}$ & $\begin{array}{c}\text { Abduction } \\
\text { (ALR vs ALD) }\end{array}$ & $\begin{array}{c}\text { Adduction } \\
\text { (ALR vs ALD) }\end{array}$ \\
\hline $\begin{array}{c}\text { Anwander } \\
\text { et al. }{ }^{12}\end{array}$ & $\begin{array}{c}102(70-130) \mathrm{vs} \\
99(70-120)\end{array}$ & $\begin{array}{c}5(0-10) \mathrm{vs} \\
5(0-10)\end{array}$ & $\begin{array}{c}36(10-75) \text { vs } \\
39(5-80)\end{array}$ & $\begin{array}{c}15(0-45) \text { vs } \\
8(0-45)\end{array}$ & $\begin{array}{c}45^{*}(30-70) \text { vs } \\
38(25-45)\end{array}$ & $\begin{array}{c}22(15-30) \text { vs } \\
20(0-40)\end{array}$ \\
\hline $\begin{array}{l}\text { Espinosa } \\
\text { et al. }^{15}\end{array}$ & \multicolumn{2}{|c|}{105 vs 96} & \multicolumn{2}{|c|}{49 vs 35} & \multicolumn{2}{|c|}{56 vs 47} \\
\hline
\end{tabular}

ALD, debridement; ALR. repair.

*Denotes statistical significance in favor of ALR. 
Table 5. Revisions

\begin{tabular}{|c|c|c|}
\hline Study & THR (ALR vs ALD) & Revision (ALR vs ALD) \\
\hline Anwander et al. ${ }^{12}$ & $6 \%$ vs $12 \%$ & $6 \%$ vs $12 \%$ \\
\hline Cetinkaya et al. ${ }^{13}$ & $6 \%$ vs $3 \%$ & $8.8 \%$ vs $6.1 \%$ \\
\hline Chen et al. ${ }^{14}$ & $10.1 \%$ vs $10.1 \%$ & $13.0 \%$ vs $14.4 \%$ \\
\hline Larson et al. ${ }^{17}$ & $2.5 \%$ vs $0 \%$ & $5.0 \%$ vs $9.1 \%$ \\
\hline Menge et al. ${ }^{18}$ & $34 \% U$ & $6.6 \%$ vs $2.7 \%$ \\
\hline Schilders et al. $2017^{19}$ & $0 \%$ vs $0 \%$ & \\
\hline
\end{tabular}

THR, total hip replacement; U, results undifferentiated between groups; ALD, debridement; ALR, repair.

noted that 2 of the included studies demonstrated that the rate of osteoarthritis progression was significantly improved with ALR relative to ALD.

The results of this review supports the results of several previous biomechanical studies, which demonstrated that ALR restores the suction seal of the normal labrum, reduces femoral head translation, and reduces acetabular contact stress. ${ }^{20,21}$ The acetabular labrum is generally thought to provide normal hip function, in part, by acting as a stabilizer to distracting forces via the "suction effect" of the hip fluid seal. Research by Nepple et al. ${ }^{20}$ and Philippon et al. ${ }^{21}$ has demonstrated that the labrum is a significantly greater stabilizer than the capsule and accounts for $70 \%$ to $77 \%$ of distraction stabilization in the hip joint. Although both labral repair and debridement are important procedures for all hip arthroscopists, the significance of repair cannot be understated.

A recent survey-based study by Herickhoff et al. ${ }^{22}$ demonstrated that 4 variables known before surgery were identified as being important to the decisionmaking of the majority of hip arthroscopists. First, $70 \%$ of surveyed surgeons felt that magnetic resonance imaging was an important deciding factor-specifically, the arthritic status of the joint. ${ }^{22}$
Second, $63 \%$ of those surveyed favored labral repair in patients $52 \pm 9.08$ years and younger, although they favored debridement in patients $54 \pm 6.41$ years and older. ${ }^{22}$ Additionally, 57\% favored repair in more active patients relative to less active ones, and 53\% favored debridement for patients with Tonnis grade 2 or 3 on $x$-ray imaging. ${ }^{22}$

These survey results are especially interesting when considering the results of a recent study by Chen et al., ${ }^{14}$ which attempted to prove that labral debridement, when used with narrow indications in select patients, had comparable 5-year outcomes to labral repair. Included patients had grade $<4$ Outerbridge chondral damage, preoperative Tonnis grade $<2$, no history of prior hip conditions or dysplasia, and no prior hip surgery. These patients were also required to have a stable labral base, at least $4 \mathrm{~mm}$ of the labral width, small focal tears with minimal intrasubstance involvement and enough stable labral tissue preserved to maintain the suction-seal function. Of note, the study demonstrated no statistically significant differences with respect to final patientreported outcome scores between these matched groups with a similar rate of complications.

Byrd and Jones. ${ }^{23}$ described that arthroscopic selective debridement could result in favorable long-term

\begin{tabular}{|c|c|c|c|c|c|c|c|c|c|}
\hline Study or Subgroup & \multicolumn{2}{|c|}{ ALR } & \multicolumn{2}{|c|}{ ALD } & Weight & $\begin{array}{c}\text { Risk Ratio } \\
\text { M-H, Random, } 95 \% \mathrm{Cl}\end{array}$ & \multicolumn{3}{|c|}{$\begin{array}{c}\text { Risk Ratio } \\
\text { M-H, Random, } 95 \% \mathrm{Cl}\end{array}$} \\
\hline Anwander 2016 & 2 & 35 & 3 & 25 & $20.8 \%$ & $0.48[0.09,2.64]$ & & $\longrightarrow$ & \\
\hline Cetinkaya 2016 & 2 & 34 & 1 & 39 & $11.0 \%$ & $2.29[0.22,24.20]$ & & & \\
\hline Chen 2018 & 7 & 69 & 7 & 69 & $62.1 \%$ & $1.00[0.37,2.70]$ & & & \\
\hline Larson 2011 & 1 & 50 & 0 & 44 & $6.1 \%$ & $2.65[0.11,63.36]$ & & & \\
\hline Schilders 2017 & 0 & 32 & 0 & 69 & & Not estimable & & & \\
\hline \multirow[t]{2}{*}{ Total $(95 \% \mathrm{Cl})$} & & 220 & & 246 & $100.0 \%$ & $1.00[0.46,2.18]$ & & & \\
\hline & & & & & & & 0.01 & 0.1 & 1 Favors ALD \\
\hline
\end{tabular}

Fig 5. Forest Plot of the rate of conversion to total hip arthroplasty. 


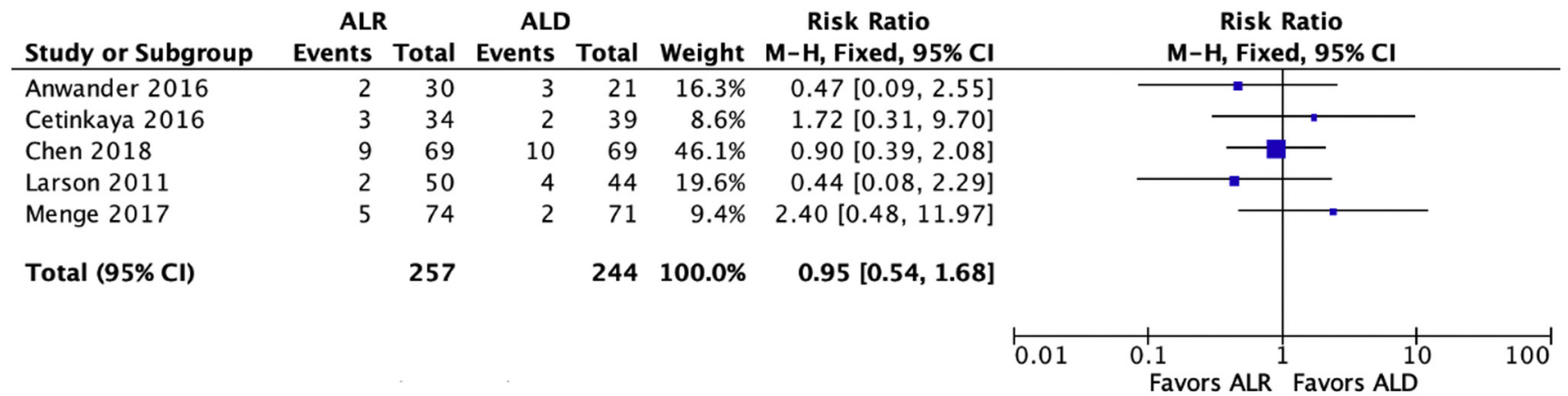

Fig 6. Forest Plot of the revision rate.

outcome supported by a 10-year follow-up in 50 patients who underwent selective labral debridement. However, it is important to note that patients among the Byrd cohort fared worse with greater arthritis of the hip joint. In cases where the extent or pattern of labral damage was not amenable to repair, debridement of the damaged labrum may not be the preferred option, as labral reconstruction with an autograft or allograft may be a superiorly effective treatment option. ${ }^{24}$ In general, it appears that there is a general trend toward the preservation of the labrum with techniques such as labral repair or reconstruction. ${ }^{25}$

Despite the numerous benefits of hip arthroscopy, the repair of the acetabular labrum is highly specialized and associated with a challenging learning curve. ${ }^{26}$ The procedure of ALD is generally less challenging than that of ALR for lower-volume surgeons, and the surgeons who performed labral debridement initially may be more likely to investigate failures of treatment or complications than those who performed repairs. On the other hand, it is possible that labral repairs were pursued selectively by more experienced and highervolume surgeons, leading to biased reporting of outcomes. ${ }^{27}$ The included studies used a variety of clinical and radiographic outcome measures. Finally, the included studies generally had a follow-up period of less than 3 years; hence, the long-term outcome of labral management remains unknown.

\section{Limitations}

This systematic review is not without its limitations. First, the majority of included studies were nonrandomized and comparative. This may increase the risk of selection bias. Forest Plots were used to compare the 2 groups with patient-reported outcomes as an endpoint. Although asking the same question, this faces limitations because the studies analyzed were retrospective and therefore subject to inherent bias. Power analyses were not conducted for the studies that did not report significance and therefore may be underpowered to demonstrate what the other studies report. Therefore conclusions interpreted from these plots must be interpreted with caution. Last, because this is a systematic review, it will contain all the limitations of the studies within it. There are multiple confounding factors when interpreting the data in each study, for example the varying length of follow-up, capsular closure, potentially increased surgeon experience, and technology of newer data versus more preliminary studies.

\section{Conclusion}

Current literature suggests that acetabular labral repair may result in superior patient-reported outcomes. However, there appears to be no significant difference in the rate of progression to total hip arthroplasty at up to 10-year follow-up.

Table 6. Complications

\begin{tabular}{|c|c|c|}
\hline Study & Complications (ALR vs ALD) & Arthritis (ALR vs ALD) \\
\hline Anwander et al. $^{12}$ & & $78 \%{ }^{*}$ vs $46 \%$ \\
\hline Cetinkaya et al. ${ }^{13}$ & $6 \mathrm{U}$ - All nerve palsies ( 2 femoral, 2 obturator and 2 pudendal) & \\
\hline Chen et al. ${ }^{14}$ & $\begin{array}{l}1.4 \% \text { ( } 1 \text { nerve palsy - Perineal) vs } 5.8 \% \text { ( } 2 \text { nerve palsy }- \text { Sciatic and lateral femoral } \\
\text { cutaneous, } 1 \text { infection, } 1 \text { pulmonary embolism) }\end{array}$ & \\
\hline Espinosa et al. ${ }^{15}$ & & $\mathrm{RNR}^{*}$ \\
\hline Schilders et al. ${ }^{19}$ & $0 \%$ vs $6 \%$ ( 3 heterotopic ossification) & \\
\hline
\end{tabular}




\section{References}

1. McCarthy JC, Noble PC, Schuck MR, Wright J, Lee J. The Otto E. Aufranc Award: The role of labral lesions to development of early degenerative hip disease. Clin Orthop Relat Res 2001:25-37.

2. Awad MAH, Bajwa AK, Slaunwhite E, Logan KJ, Wong IH. Indications for hip arthroscopy in pediatric patients a systematic review. J Hip Preserv Surg 2019;6: 304-315.

3. Shapira J, Kyin C, Go C, et al. Indications and outcomes of secondary hip procedures after failed hip arthroscopy. A systematic review. Arthroscopy 2020;36:1992-2007.

4. Nasser R, Domb B. Hip arthroscopy for femoroacetabular impingement. EFORT Open Rev 2018;3:121-129.

5. Sogbein OA, Shah A, Kay J, et al. Predictors of outcomes after hip arthroscopic surgery for femoroacetabular impingement: A systematic review. Orthop J Sports Med 2019;7:2325967119848982.

6. Philippon MJ. New frontiers in hip arthroscopy: The role of arthroscopic hip labral repair and capsulorrhaphy in the treatment of hip disorders. Instr Course Lect 2006;55: 309-316.

7. Haviv B, O’Donnell J. Arthroscopic treatment for acetabular labral tears of the hip without bony dysmorphism. Am J Sports Med 201 1;39:79S-84S (Suppl).

8. Ferguson SJ, Bryant JT, Ganz R, Ito K. An in vitro investigation of the acetabular labral seal in hip joint mechanics. J Biomech 2003;36:171-178.

9. Ferguson SJ, Bryant JT, Ganz R, Ito K. The influence of the acetabular labrum on hip joint cartilage consolidation: A poroelastic finite element model. J Biomech 2000;33: 953-960.

10. Liberati A, Altman DG, Tetzlaff J, et al. The PRISMA statement for reporting systematic reviews and metaanalyses of studies that evaluate healthcare interventions: explanation and elaboration. BMJ 2009;339: b2700.

11. Slim K, Nini E, Forestier D, Kwiatkowski F, Panis Y, Chipponi J. Methodological index for non-randomized studies (minors): Development and validation of a new instrument. ANZ J Surg 2003;73:712-716.

12. Anwander H, Siebenrock KA, Tannast M, Steppacher SD. Labral reattachment in femoroacetabular impingement surgery results in increased 10-year survivorship compared with resection. Clin Orthop Relat Res 2017;475: 1178-1188.

13. Cetinkaya S, Toker B, Ozden VE, Dikmen G, Taser O. Arthroscopic labral repair versus labral debridement in patients with femoroacetabular impingement: A minimum 2.5 year follow-up study. Hip Int 2016;26:20-24.

14. Chen AW, Yuen LC, Ortiz-Declet V, Litrenta J, Maldonado DR, Domb BG. Selective debridement with labral preservation using narrow indications in the hip:
Minimum 5-year outcomes with a matched-pair labral repair control group. Am J Sports Med 2018;46:297-304.

15. Espinosa N, Rothenfluh DA, Beck M, Ganz R, Leunig M. Treatment of femoro-acetabular impingement: Preliminary results of labral refixation. J Bone Joint Surg Am 2006;88:925-935.

16. Krych AJ, Thompson M, Knutson Z, Scoon J, Coleman SH. Arthroscopic labral repair versus selective labral debridement in female patients with femoroacetabular impingement: A prospective randomized study. Arthroscopy 2013;29:46-53.

17. Larson CM, Giveans MR, Stone RM. Arthroscopic debridement versus refixation of the acetabular labrum associated with femoroacetabular impingement: Mean 3. 5-year follow-up. Am J Sports Med 2012;40:1015-1021.

18. Menge TJ, Briggs KK, Dornan GJ, McNamara SC, Philippon MJ. Survivorship and outcomes 10 years following hip arthroscopy for femoroacetabular impingement: Labral debridement compared with labral repair. J Bone Joint Surg Am 2017;99:997-1004.

19. Schilders E, Dimitrakopoulou A, Bismil Q, Marchant P, Cooke C. Arthroscopic treatment of labral tears in femoroacetabular impingement: A comparative study of refixation and resection with a minimum two-year follow-up. J Bone Joint Surg Br 201 1;93:1027-1032.

20. Nepple JJ, Philippon MJ, Campbell KJ, et al. The hip fluid seal-Part II: The effect of an acetabular labral tear, repair, resection, and reconstruction on hip stability to distraction. Knee Surg Sports Traumatol Arthrosc 2014;22: 730-736.

21. Philippon MJ, Nepple JJ, Campbell KJ, et al. The hip fluid seal-Part I: The effect of an acetabular labral tear, repair, resection, and reconstruction on hip fluid pressurization. Knee Surg Sports Traumatol Arthrosc 2014;22:722-729.

22. Herickhoff PK, Safran MR. Surgical decision making for acetabular labral tears: An international perspective. Orthop J Sports Med 2018;6:2325967118797324.

23. Byrd JW, Jones KS. Prospective analysis of hip arthroscopy with 10-year followup. Clin Orthop Relat Res 2010;468:741-746.

24. Trivedi NN, Sivasundaram L, Su CA, et al. Indications and outcomes of arthroscopic labral reconstruction of the hip: A systematic review. Arthroscopy 2019;35:2175-2186.

25. Westermann RW, Day MA, Duchman KR, Glass NA, Lynch TS, Rosneck JT. Trends in hip arthroscopic labral repair: An American Board of Orthopaedic Surgery Database Study. Arthroscopy 2019;35:1413-1419.

26. Konan S, Rhee SJ, Haddad FS. Hip arthroscopy: Analysis of a single surgeon's learning experience. J Bone Joint Surg Am 2011;93:52-56 (Suppl 2).

27. Souza BG, Dani WS, Honda EK, et al. Do complications in hip arthroscopy change with experience? Arthroscopy 2010;26:1053-1057. 